\title{
Sperm Motility Measurement
}

National Cancer Institute

\section{Source}

National Cancer Institute. Sperm Motility Measurement. NCI Thesaurus. Code C102281.

The determination of the amount of sperm capable of forward, progressive movement present in a semen sample. 